Juan Carlos Flores Rivas*

\title{
Límites Constitucionales de las Facultades Interpretativas de los Organismos de la Administración
}

\section{1.- Análisis de la Preceptiva Constitucional}

En la lectura del Texto Constitucional podemos encontrar múltiples preceptos que atienden a la estructuración del poder, a la forma de ejercerlo y a la conjugación de éste, con el respeto de las garantías y derechos que emanan de la naturaleza humana. Sin embargo, no encontramos una norma expresa y específica que nos ilumine en la búsqueda de los fundamentos constitucionales de las facultades interpretativas de los Organos de la Administración.

No obstante, en un Estado de Derecho donde la Constitución goza de supremacía jerárquica sobre todo el ordenamiento jurídico, el Estado y sus Organismos se encuentran sometidos de manera plena e integral a derecho, tanto en su ser como en su obrar'.

Lo anterior no admite excepción alguna, ya que en la Carta Fundamental aparecen disposiciones claras destinadas a preservar el principio de juridicidad en la actuación de los órganos estatales.

Es así como la Constitución señala, en el artículo 6 el principio de supremacía constitucional. Dicho precepto constituye el eje en torno al cual gira el Principio de Supremacía Constitucional y la sujeción irrestricta a la Carta Fundamental y a las normas dictadas conforme a ella.

"Ayudante

de Derecho

Constitucional.

Universidad de Los

Andes.

Soto Kloss Eduardo, Derecho administrativo Bases Fundamentales Principio de Jtridicidad. Ed. Jurídica, Santiago, 1996, T. II, p. 24. 
En otras palabras la "Carta Fundamental estableció el principio de su preeminencia e impuso la sujeción de todos los órganos del Estado, sin excepción, a las normas dictadas conforme a ella, [...] consagró la vinculación integral al ordenamiento juridico público, genterado a partir de su texto, respecto de todas las autoridades, personas, grupos o instituciones".

Con todo, la Constitución dio un paso más, al establecer un marco normativo aplicable al legítimo ejercicio de los derechos y garantías constitucionales, limitando y compeliendo los eventuales atentados de que puedan ser objeto.

Al respecto, es menester destacar el "principio de Reserva Legal", en virtud del cual determinadas marerias, dentro de las cuales se incluyen las garantías constitucionales, sólo pueden ser abordadas por normas de rango legal y jamás por preceptos de inferior jerarquía.

Este principio es una auténtica garantía sustantiva, para los gobernados y el resguardo de sus derechos fundamentales. Una prueba irrefutable de la protección que quiso dar el Constituyente a los derechos y garantías, se aprecia de modo inequivoco en el rexto del artículo $19 n^{\circ} 26$.

Tales preceptos deben ser regulatorios o complementarios de los derechos, libertades y garantias, o limitativos de ellos, tornándose imperativo en los dos primeros casos que la Constitución lo haya directa, expresa y previamente mandado, mientras que tratándose de una limitación ella exige que lo haya autorizado con idénticas modalidades ${ }^{3}$.

Este límite constitucional afecta al legislador, pero con mayor razón a los Organismos de la Administración, por la preponderancia que la Constitución y la ley ostentan sobre las normas administrativas, que incluso las primeras son las normas habilicantes de coda actuación administrativa.

El Tribunal Constitucional, respecto del principio de reserva legal ha señalado:

“... reserva a la ley y sólo a ella, regular los modos de adquirir el dominio y las limitaciones y obligaciones que deriven de su función socials sólo la ley puede establecer limitaciones para la adquisición del dominio de alguna clase de bienes; a la ley se reserva la regulación de actividades económicas licitas; solo ella puede establecer nuevos tributos y restringir el ejercicio de determinados derechos y libertades para proteger el medio ambiente. El fortalecimiento de la reserva a la ly en materia de derechos fundamentales se aprecia con intensidad en el articulo 60 No 2 que dispone ssólo son materias de ley: las que la Constitución exija que sea reguladas por una leys; en el articulo 61 que no permite al Congreso Nacional delegar facultades legislativas al Presidente de la Republica en materias comprendidas en las garantias fundamentales". (Sentencia Rol 244 de 26 de agosto de 1996).

= Caldera Delgado Hugo, "Limires Constitucionales de la Discreciunalidad Administrativa". en Revista Chilena de Derecho, Vol. 16, 1989, p. 423.

- Cea Egaña José Luis, "Hermenéutica Constitucional, Soberania legal y Discrecionalidad Administrativa", en Revista Chilena de Derecho, Vol. 11, 1984, p. 11. 
Sin embargo, en los últimos años se ha generado un proceso de relativización de la reserva de ley, otorgándole al reglamento una labor crucial en la regulación, complementación $e$ incluso en la limitación de los derechos fundamentales, en base a distintos pasajes del Texto Fundamental, como el dominio máximo legal, la intensidad de reservas establecidas en la Constitución y la naturaleza del Reglamentót.

La potestad reglamentaria, en palabras de don Alejandro Silva Bascuñán, consiste en: "La facultad otorgada al Presidente de la República para emitir toda especie de órdenes, encaminadas a satisfacer, en la amplitud de su proyección, La vastísima tarea que le entrega La Carta y que no tiene más limitaciones que la de someterse a la Constitución y a las leyes y la de no dictar normas que pertenezcan a la función legislativa ${ }^{5}$.

Al respecto la Carta Fundamental, consagra la potestad reglamentaria en el artículo $32 \mathrm{~N} \circ 6$ que señala:

"Son atribuciones especiales del Presidente de la Republica: 60 Ejercer la potestad reglamentaria en todas aguellas materias que no sean propias del dominio legal, sin periuicio de la facultad de dictar los demás reglamentos, decretos e instrucciones que crea conveniente para la ejecución de las leyes".

La doctrina distingue entre potestad reglamentaria autónoma y de ejecución. $\mathrm{La}$ primera tiene como finalidad dictar disposiciones generales o especiales no reservadas a] dominio legal y se le da el nombre de potestad reglamentaria ampliada, pues ésta es la que se ejerce en materias que no son propias del dominio legal, constituyendo la fuente residual del orden jurídico, salvo lo que se regla por la Constitución o la ley, es regulado por la potestad reglamentaria aurónoma ${ }^{6}$.

En cambio, mediante la potestad reglamentaria de ejecución el Presidente de la República lleva lo general o abstracto de la ley a lo parricular y concreto de su obediencia y cumplimiento, con el objeto de satisfacer los objerivos perseguidos por la Constitución y la ley'.

4 Carmona Sintander Carlos, "Lin nuevo estudio en la relación Ley-Regiamento: El Ímbito del Regharmento": cn Revista de Derterto Pśbilico, Vol. 63, 2002, pp. 158-15\%.

Silva Baxunán Alejandro, Tratudo de Derecho Constitucional. La Constitución de 1980. Gobierno. Ed. Juridica, Sankiago, 2000, l.Y, p. 126.

S F.yans Fspiñeira Fugerio, "I.a I.ey, Su Fijecución y La Interpreración Normativa por Los Otganos del Estado", en Revista de Derecho Público. Vol. 65, 2003. p. 67.

Ídem, p. 68. 


\section{2.- Fundamentos Normativos de las Potestades Interpretativas de la Administración}

Cuál es el fundamento de las potestades interpretativas de los Órganos de la Administración?

Una parte de la doctrina, representada por el profesor de derecho administrativo Enrique Silva Cimma, a propósito del Decreto de Insistencia de los Decretos Supremos y de las Resoluciones de los Jefes de Servicios que deban tramitarse por la Contraloría General de la República y de la porestad reglamentaria de los Entes Autónomos, entiende que las facultades normativas o interpreativas de los Organismos de la Administración se encuentran comprendidas en el numeral $6^{\circ}$ del arrículo 32 del Código Político, señalando que:

"La ley entrega generalmente a los jefes de los servicios de la Administración Pública la atribución de dictar decretos o resoluciones sobre las materias de su competencia o que digan relación con el personal de sus respectivos servicios. En estos casos, dichas atribuciones no son otra cosa que derivaciones de la facultad del Presidente de la República, que se entrega a stus subordinados a fin de hacer posible una administración publica activa y diligente ${ }^{\text {. }}$.

El autor anteriormente citado, entiende que el Presidente de la República al ser investido constitucionalmente de la potestad reglamentaria para ejecutar las leyes o para dictar normas reglamentarias en las áreas comprendidas fuera del dominio legal, puede delegar en los Organismos de la Administración dicha potestad para que éstos dicten normas dentro del ámbito de su competencia, debido a que dichos Organismos son colaboradores del Presidente en el Gobierno y la Administración del Estado, según prescribe el artículo 24 de la Carta Fundamental.

En discrepancia con el autor anteriormente citado, se encuentra don Alejandro Silva Bascuñán, el cual sostiene:

"La potestad reglamentaria inherente a los cuerpos administrativos funcionalmente descentralizados tiene su fuente en la respectiva ley de creación de cada uno de ellos y no proviene, por lo tanto, de delegación alguna del Presidente. El legislador, al crear dichos entes, no puede menos que darles facultades para adoptar las decisiones de carácter general o particular encaminadas a satisfacer sus respectivos objetivos, con prescindencia de la voluntad del lefe del Estado, de guien no dependen, y ajenas, por lo tanto, a la potestad reglamentaria de éste.

Si entendemos que las potestades normativas de los Órganos de la Administración provienen de la delegación que realiza el Presidente de la República, se estaria facultando al Jefe de Estado para otorgar mayores atribuciones y potestades que aquellas

s Silva Cimma Enrique, Derecho Administrativo Chileno y Cumparado. Ed. Juridica, Santiago, 4́a edición, 1496 . T. I. pp. 250-251. En el mismo sentido, en las páginas 175-177.

, Silva Basiuñán Alejandro, ob. cir.. Nol6, p. 174. 
explícitamente establecidas por la respectiva ley para los cuerpos administrativos autónomos y funcionaimente descentralizados, lo cual viola de manera flagrante el Texto Constitucional.

Recordemos que la atribución de potestades, sean éstas normativas, fiscalizadoras, interpretativas o sancionatorias, en nuestro ordenamiento jurídico debe hacerse mediante la Constitución o en su defecto por la ley, ello por el principio de juridicidad que constituye la regla de oro del derecho público, en virtud de la cual los Organismos de la Administración del Estado sólo pueden hacer aquello que está expresa, especifica y detalladamente arribuido en la ley o en el Código Politico, so pena de nulidad, lo cual es una garantía para el administrado.

Sin perjuicio de lo anterior, el articulo 32 No 6 de la Carta Fundamental señala que la potestad reglamentaria del Presidente de la República tiene como objeto ejecutar las leyes, mediante la dictación de reglamentos, decretos e instrucciones que crea convenientes. Dicha potestad es atribuida al Presidente de la República de manera directa por el Texto Constitucional, sin intermediación de una ley, configurándola como la norma de clausura del ordenamiento jurídico ${ }^{10}$.

Por lo tanto, en ningún pasaje de la Constitución se señala que la potestad reglamentaria sea una fuente de arribución de porestades para con los servicios públicos, ya que en un Esrado de Derecho éstas sólo pueden ser establecidas en virtud de la Constitución $y$ de la Ley.

Por otra parre, si acogemos la interpretación sustentada por el profesor Enrique Silva Cimma, se generan una serie de inconvenientes a nivel de la Ley Orgánica Constitucional de Bases Generales de la Administración del Estado $\mathrm{N}^{\circ} 18.575$, la cual en el artículo $41^{\circ}$ regula la delegación del ejercicio de las atribuciones y facultades propias y señala una serie de requisitos dentro de los cuales es útil destacar los siguientes:

- La delegación deberá ser parcial y recaer en materias especificas:

- Los delegados deberán ser funcionarios de la dependencia del delegante;

- El acto de delegación deberá ser publicado o notificado según corresponda;

- La delegación será esencialmente revocable;

- El delegante no podrá ejercer la competencia delegada sin que previamente revoque la delegación.

Por lo tanto, la delegación de la pocestad reglamentaria del Presidente de la República debe ser sólo respecro de su ejercicio y no de la potestad misma; debe ser parcial y en materia especifica, esto es sólo una parte de ella y no sobre la globalidad de sus

:" Cea Egaña José Luis, "Dominio Legal y Reglamentario en la Constjución de 1980" en Revista Chilena de Derecho. Vol. 11, 1984, p. 430. 
atribuciones, a mayor abundamiento el organismo delegado no puede dictar normas generales como reglamentos, circulares u ordenanzas, y por último la delegación es esencialmente revocable, lo que deriva en que los Organismos de la Administración con facultades normativas producen incertidumbre y desconfianza en los entes sujetos a su fiscalización, porque la potestad que ejercen está sujeta a revocación por el Jefe de Estado; en conclusión, el Presidente de la República revocaría potestades otorgadas por una ley a través de un acto administrativo.

En razón de lo anterior, creemos que las facultades interpretacivas de los Organismos de la Administración arrancan del Texto Constitucional, pero no como una derivación o delegación de la potestad reglamentaria del Presidente de la República, sino que de la respectiva ley de creación del organismo y asi lo entiende un sector de la doctrina:

"Por regla general las superintendencias son órganos autónomos, a veces funcionalmente descentralizados, pero en todos los casos con potestades interpretativo-normativas establecidas en la respectiva ley de creación, por lo que la babilitación competencial para dictar normas obligatorias a los particulares y entes fiscalizados emana de esa fuente y no de una derivación de la facultad atribuida al lefe de Estado para dictar reglamentos, decretose instrucciones que crea conveniente para la ejecución de las leyes ${ }^{\text {"II }}$.

A mayor abundamiento, creemos que el fundamento constitucional de las potestades interpretativas de la Administración del Estado arranca del artículo $7^{\circ}$, inciso 2 de la Carta Fundamental, cuando se refiere a que ninguna magistratura podrá atribuirse ni aun a pretexto de circunstancia extraordinaria otra autoridad o derechos que los que expresamente se les hayan conferido en virtud de la Constirución o las leyes. Por lo tanto, al señalar a la ley como una fuente de atribución de potestades es ella la que les otorga a los Organismos de la Administración las facultades interpretativas; obviamenre esta ley no puede otorgar facultades interpretativas sobre materias que excedan el dominio máximo legal de conformidad con el artículo 63 de la Carta.

La ley que atribuye potestades interpretarivas a los Organismos de la Administración, es de iniciariva exclusiva del Presidente de la República en virrud del artículo 65, inciso $4^{\circ}, \mathrm{N} 02$ de la Constitución que señala que el Presidente de la República tiene la iniciativa exclusiva para determinar las funciones $y$ atribuciones de los servicios públicos. La Constitución no atribuye potestades interpretativas a los Organismos de la Administración del Estado, sino que es la ley de creación del servicio respectivo la cual los inviste de dichas facultades de conformidad al artículo 7 , inciso $2^{\circ}$ de la Carta Fundamental en relación con el artículo 63 No14 que se remite a las leyes de iniciativa exclusiva del Presidente de la República entre las cuales se encuentra la creación de servicios públicos, la determinación de sus funciones y atribuciones, según el anteriormente citado artículo 65 , inciso $4 \mathrm{~N}^{\circ} 2$ de la Constitución.

\footnotetext{
Evans Espiñeira Eugenio, "1 a Ley, Su Ejecución y La Interpretación Normativa por Los Organus del Estado", en Revista de Derecho Priblico. Vol. 65, 2003, p. 68.
} 
La Constitución no atribuye potestades interpretativas a la Administración, sino que es la ley la facultada para hacerlo y de hecho lo hace como se verá más adelante; ahora cabe preguntarse, ça ley al atribuir potestades interpretativas a los Organismos de la Administración se ajusta a la Constitución? o dicho de otra forma, es constitucional que la ley atribuya facultades interpretativas a los Organismos de la Administración? O también: jla facultad de interpretar la ley se encuencra radicada constitucionalmente de manera privariva en el legislador o puede otra norma jurídica ororgar porestades interpretativas a la Administración y ser igualmente válida ante la Constitución?

\section{1) Interpretación Auténtica.}

Como vimos en la primera parte de esta investigación, la interpretación auténtica es la que realiza el órgano creador de los preceptos interpretados de un modo generalmente obligatorio, o en palabras de Agustín Squella, "Es la que de la ley lleva a cabo el propio órgano productor de las leyes, esto es, el órgano o poder legislativo, ya sea que lo haga en el propio texto de la ley interpretada o valiéndose de una ley posterior que toma por ello el nombre de ley interpretativa. ${ }^{\text {"I2 }}$, como por ejemplo el legislador en nuestro ordenamiento jurídico, en virtud del artículo 3 inciso $1^{\circ} \mathrm{del}$ Código Civil es llamado a interpretar la ley de un modo general y obligatorio. Ahora bien, la disposición que encarga al legislador la interpretación auréntica u obligatoria de la ley es jerárquicamente considerada una ley pura y simple, por lo tanto, el mismo legislador podría encregar esa facultad en otro órgano, como los de la Administración como ocurre en la práctica, sin embargo aquí nos pondremos en la hipótesis que la interpretación auténtica de la cual está investido el legislador, no sólo se encuentra en el Código de Bello, sino que arranca su fundamento de la propia Constitución.

\subsection{1) Interpretación Auténtica Encargada Directamente por la Constitución.}

Anteriormente cuando nos encontrábamos en busca de los fundamentos normativos de las potestades interpretativas de los Organismos de la Administración del Estado, concluiamos que la Carta Fundamental nada señalaba al respecto y que dichas potescades encontraban su explicación normativa en la habilicación que realiza la Constitución a la ley para que establezca derechos o autoridades de conformidad con el artículo 7, inciso $2^{\circ}$, puesto en relación con los artículos 63 y 65 del Código Supremo.

Sin embargo, al preguntarnos sobre los fundamentos normativos de la facultad del legislador para interpretar auténticamente la ley con carácter general y obligatorio, nos encontramos con la sorpresa que la norma habilitante de dicha potestad en principio es la ley, especificamente el Código Civil en su arrículo $3^{\circ}$, y no la Constitución, digo en principio porque puede ser que de una interpretación constitucional derivemos en una conclusión distinta a la antes señalada. 
Al leer la Carta Fundamental, principalmente en el Capítulo V que regula al Congreso Nacional, nos podemos dar cuenta que los preceptos constitucionales sólo se refieren a cuestiones orgánicas y atribuciones que atañen a las relaciones que existen entre el Gobierno y el Congreso Nacional, como las normas relativas a la acusación constitucional, la fiscalización parlamentaria, etc. Por lo tanto, no existe una norma constitucional expresa que señale que el poder legislativo tiene la facultad de interpretar la ley de modo generalmente obligatorio, ello sin considerar el reconocimiento que se hace al Congreso Nacional para dictar leyes, de lo cual se puede concluir que a primera vista la facultad interpretativa del poder legislativo sólo tiene fundamento en el Código Civil.

Sin perjuicio del razonamiento anterior, se puede señalar que la Carta Fundamental de 1980 introduce tres nuevos tipos de leyes, entre las cuales nos interesan las Leyes Interpretativas de la Constitución. Estas normas se encuentran reguladas en el artículo 66 de la Constitución que nos señala el quórum de aprobación, modificación y derogación de los preceptos que interpreten alguna norma constitucional, pero aunque no nos da un concepto de leyes interpretativas ${ }^{13}$, nos permitirá argumentar que la facultad interpretativa auténtica del legislador encuentra su fundamento en la propia constitución.

Continuando con el razonamiento anterior, señalamos que la Carta Fundamental al aproximarnos al concepto de ley interpretariva de la Constitución, por lo menos desde la perspectiva de su quórum permite reflexionar acerca del fundamento constitucional de la interpretación legislativa, ello porque si la Constitución señala que las leyes que interpreten algún precepto constitucional requieren de un determinado quórum, lo que me está diciendo, es que para interpretar la Constitución se requiere de una ley, o en otras palabras si la facultad de interpretar el Texto Supremo del ordenamiento jurídico le fue otorgada al legislador, con mayor razón esta facultad alcanza al resto del ordenamiento jurídico.

Al respecto Pablo Rodríguez Grez señala que "Las leyes, en cierta medida, no son más que la extensión de los grandes principios consagrados en la Constitución. Es cierto que quienes legislan pueden desenvolverse en un amplio campo para gestar las leyes, pero no pueden ni material ni formalmente, contravenir los principios constitucionales que obedecen a la voluntad del constituyente. El proceso legislativo es, en medida importante y necesariamente, interpretativo, en cuanto amplia, desarrolla, extiende e inspira las leyes en las directrices constitucionales." 14

13 La Corte Suprema ha dado un concepto de ley interpretariva, señalando: "La ley interpretativa es aquella que establece una versión univoca frente a la situación de pluralidad de sentidos contenidos en otra leys ella se limita a esclarecer el signiffcado y contenido real de un pensamiento juridico ya encerrado en la forma primitiva, sin traer algo nuevo al precepto interpretado ni aportar elementos juridicamente innovatorios, puesto que declura cuál ha sido siempre el verdadero sentido de la ley" (C. Suprema, 28 septiembre 1994, R.G.J. №171, pág. 61).

14 Rodríguez Grez Pablo, "Interpretación, Creación y Desviación en el Proceso de Generación de las Normas" en Interpretación, Integración y Razonamiento Jurídico, Congreso realizado por la Universidad de Chile y la Universidad Adolfo Ibáñez. Ed. Jurídica, 1991, p. 194. 
Por lo tanto, es la ley la llamada constitucionalmente a interpretar la Carta Fundamental mediante las leyes interpretativas, las cuales según Agustín Squella deben entenderse incorporadas a la Constitución, cuya facultad se extiende al resto del ordenamiento jurídico, por lo tanto bajo este análisis el Código Civil seria reirerativo en señalar que sólo toca al legislador explicar o interpretar la ley de un modo generalmente obligatorio. Lo anterior es ratificado por la propia historia fidedigna, establecida por la Comisión de Essudios según se señalará posteriormente en esta investigación.

Ya tenemos un primer argumento para señalar que la facultad del legisłador de interpretar la ley de manera auténtica no sólo encuentra su fundarnento en normas civiles, sino también constitucionales, como dijimos en el artículo 66. Pero este precepto no es el único que regula el fundamento de la interpretación auténtica del legislador, sino que debemos mencionar otros.

Si bien nuestro ordenamiento constitucional estableció un dominio máximo legal, este último se encuentra atenuado según señala la doctrina: "el articulo 60 (actual articulo 63) establece dos principios: a) el principio de que solo la ley puede reglar dichas materias (principio de exclusividad); y b) el principio de que sólo esas materias pueden ser reguladas por ley (principio de exclusión). Sin embargo, el $N^{0} 20$ del art. 60 pareciera desmentir el carácter taxativo de la enumeración, al establecer que es materia de ley toda otra norma de carácter general y obligatoria que estatuya las bases esenciales del ordenamiento juridico." ${ }^{\text {Is }}$

A mayor abundamiento, el numeral 20 del artículo 63 de nuestra Constitución es el único precepto constitucional que nos da una definición de lo que debemos entender por ley, señalando que es todo otra norma de carácter general y obligatorio que estaruya las bases esenciales del ordenamiento juridico, por lo tanto el dominio máximo legal se flexibiliza por este precepto al punto que se puede llegar a pensar que incluso se entenderian incorporadas en este concepto las normas reglamentarias.

Sin perjuicio de lo anterior, el numeral 20 del artículo 63, nos permire señalar otro argumento para pensar que la facultad de interpretación auténtica del legislador tiene raigambre constitucional, ello porque si pensamos que dicho numeral nos deja abierta la posibilidad de que el legislador mediante las leyes interpretarivas estatuya las bases esenciales del ordenamiento juridico, es decir cualquier norma legal que dicte el legislador en el ejercicio de sus facultades interpretativas y siempre y cuando goce de generalidad y siente las bases esenciales del ordenamiento jurídico quedará comprendida dentro del concepto constitucional de ley y por lo ranto, se entendería que la facultad de interpretar las leyes de un modo generalmente obligatorio arranca de la Constitución. 
El legislador al dictar una norma general y obligatoria que estatuya las bases esenciales de ordenamiento jurídico, mediante una ley interpretativa fjja el verdadero sentido $y$ alcance del precepto interpretado, por lo tanto la norma interpretativa se entiende incorporada a la interpretada formando un todo armónico e indivisible, asi llegamos a la conclusión de que la Constitución otorga la facultad de interpretar auténticamente al legislador, y éste dicta normas interpretativas que gozan de generalidad y obligatoriedad y que son esencialmente estatutarias del ordenamiento juridico, se incorporan a la norma interpretada y pasan a forma parte del concepto de ley comprendido en el numerał 20 del artículo 63 de la Carta.

En este sentido, es menester citar a un ilustre jurista de antaño, don Jorge Hunneus, para dar fuerza a nuestro argumento, quien en su obra "La Constitución ante el Congreso", señaló: "Si la Constitución no ba conferido al Congreso la facultad de resolver, de una manera general y obligatoria, las dudas que ocurrieren sobre la inteligencia de sus disposiciones, es claro que esa facultad sólo babría podido ejercerla el Poder Constituyente porque sólo quien dicta un precepto puede interpretarlo de un modo general y obligatorio." 16

Ahora bien es cierto que el legislador no ha dictado la Constitución, sin embargo, es el único poder autorizado para interpretar la ley de un modo general, entre ellas la Constitución. A mayor abundamiento la Constitución lo llama a dictar normas que interpreten los preceptos constitucionales, pero le fija límites dentro de los cuales ha de desarrollar la labor hermenéurica, así lo señala don José Luis Cea Egaña: "De lo cual se colige que si el Poder Constituyente delega en el Poder Legislativo la facultad de interpretar los mandatos del primero, simultáneamente ba de trazarle los limites sustantivos y procesales que reduzcan en lo posible el eventual falseamiento del sentido objetivo de los principios y normas de la Constitución." ${ }^{\prime \prime}$

Por lo canto, es la ley la única norma jurídica que puede interpretar de un modo generalmente obligatorio para todas las personas, instituciones o grupos, es decir la interpretación general del ordenamiento jurídico lo hace la ley y la norma habilitante de esta atribución es la Constitución, por lo cual el poder legislarivo puede “... reconsiderar sus propias leyes, sea para modificarlas, sea para interpretarlas, determinando su sentido, su propósito, la mens legis. (...) a diferencia de la nueta norma, la norma interpretativa nada crea; sólo aclara; pero al aclarar, tal interpretación hace retrotraer al momento de su sanción los efectos juridicos que esa ley ha generado. En este sentido, la ley interpretativa puede modificar situaciones juridicas generadas; pero la ley no lo hace entonces con el propósito de innovar, sino salvar el error de aplicación." $1 \mathrm{~s}$

is Hunncus Jorge, La Constinusion ante el Congreso. Imprenta Cervantes, Segunda Edición, Sanciago, 1891, p. 398.

1. Cea Egańa Josć Luis, "Bases para la interpretación aurénicica de la Constitución", en Revista Chilena de derecho, Vol. 5-6, 1979, 2.287.

19 Linares Quinta Segundo, Reglas para la Interpretación Constitucional. Ed. Plus Litra. Buenos Aires, 1987. P. $20-23$. 


\subsection{2) Interpretación Auténtica Encargada por La Ley.}

Ésta es la posición que sostiene la mayoría de la doctrina nacional, así por ejemplo don Carlos Ducci señala que "La interpretación efectuada por el legislador no está sujeta a norma alguna, porque emana precisamente de su facultad de dictar preceptos legales, (.) la obligatoriedad de la interpretación auténtica determinó que en varias ocasiones se quisiera limitar la libertad de interpretar las leyes atribuyéndosela exclusivamente al legislador." 19

Se atribuye de modo expreso la facultad de explicar e interpretar de manera auténtica las normas legales al propio ente que ha contribuido en su generación mediante una norma legal, es decir, se le atribuye la interpretación auténtica de las normas jurídicas al legislador, pero mediante una ley pura y simple. Sin embargo, es menester aclarar que nos teferimos a la interpretación que el ente legislativo realiza de la ley y no de la Constitución ni de los actos administrativos, ya que respecto de aquélla la facultad interpretativa emana directamente de la Carta Fundamental y respecto de éstos se concluye que si el legislador es el encargado de interpretar la ley de un modo generalmente obligatorio, puede por el principio de jerarquía normativa interpretar de la misma forma las normas que emanan de la potestad reglamentaria.

En este acápite nos ponemos en la hipótesis de señalar que si es una ley pura y simple la que atribuye la facultad de interpretar de manera auténtica las normas legales al legislador, éste puede de la misma manera atribuir dicha facultad, bajo la figura de potestad a los Organismos de la Administración del Estado para que interpreten la ley en forma administrativa dentro de su competencia.

Asi lo pensaba el profesor Carlos Ducci, quien creía que el artículo 3 inciso $1^{\circ}$ del Código Civil sólo renía jerarquja legal y no constitucional, por to que nada obsta que otra ley faculte a determinados Organos de la Administración para inrerpretar textos legales de un modo general y obligatorio, esto es, interpretar administrativamente los preceptos legales. ${ }^{20}$

Entendida esta última por la comunidad dogmática nacional como "... aquella que efectiua la autoridad administrativa en cuanto órgano de aplicación del derecho. Constituyendo asi una categoria de interpretación por via de autoridad. diferente a la que realiza el legislador y el juez. Se ba pretendido establecer el significado de la interpretación administrativa atendiendo exclusivamente al sujeto que la emite, (.) por ello me parece más pertinente entender que la interpretación administrativa es privativa de ciertos servicios puiblicos especialmente facultados por el sistema juridico para interpretar la ley. "\#।

\footnotetext{
Ducci Claro Carlos, Inteppresación furídica. Fd. Juridica, 2edición, 1993 Santiago, p. 34.

fdem, p. 42 y 161 .

Lizarna Poraa Luis, La Dirección del Trabajo: Lna Explicación de su Faculcad de Interpresar la Legislación Laboral Chilena. Tesis (Grado de Magister en Derecho), Lniversidad de Chile, Santiago, 1998, p. 35-38.
} 
En el mismo sentido, don Carlos Ducci en su obra Interpretación Jurídica propone que frente a la insuficiencia del modelo actual es mejor distinguir entre la interpretación que realiza el legislador y la efectuada por un órgano de aplicación, entiendo por tal, la interpretación judicial y la interpretación administrativa.

Realizando una primera aproximación, podemos señalar que la interpretación administrativa es una interpretación por vía de autoridad, debido a que es obligatoria para sus destinatarios, sin embargo se deben realizar una serie de consideraciones previas, tales como precisar si la interpretación administrativa constituye una interpretación auténtica de la ley o no si la interpretación administrativa es obligatoria y qué tipo de interpretación es obligatoria y cuál no. Además, debemos distinguir tanto las normas generales que dictan los Organismos de Interpretación, como las normas particulares y como también si esas normas son dictadas de oficio o a petición de un particular. Una vez contestadas estas preguntas podremos afirmar qué clase de interpreración administrativa es obligatoria y cuál sólo constituye un consejo para los administrados.

Tal como se señaló precedentemente es el legislador por medio de una ley pura y simple quien le atribuye potestades de interpretación; de la misma manera, es el propio Organo Legislativo quien entrega tal facultad a los Organismos de la Administración. Ante tal panorama cabe hacer la siguiente reflexión: ja Administración puede interpretar con la misma generalidad y abstracción que el legislador o ésta se encuentra limitada de manera más estricta que el Organo Legislativo?

Pecando de exegéticos diríamos por qué no, si ambas facuitades emanan de la ley de igual jerarquía, por lo tanto no existiría superposición de la interpretación de un órgano por sobre el otro, máxime cuando uno de ellos habilita expresamente al otro a incerpretar administrativamente la ley, es decir son igualmente válidas ambas interpretaciones, pues las dos encuentran un sustento jurídico normativo.

Incluso más, ante la Carta Fundamental ambas interpretaciones son igualmente válidas y ajustadas a derecho, ya que el Texro Supremo no ha atribuido a ningún Órgano del Estado la potestad exclusiva y excluyente de interpretar la ley. En el único aspecto que la Constitución ha sido majadera, es que el ejercicio de los derechos fundamentales sea regulado por la ley, así lo afirma categóricamente Eduardo Soto Kloss, "... sino es consecuencia de la propia Constitución, la cual en algunas materias encarga expresamente al legislador y a nadie más, de modo exclusivo y excluyente, que las regule, como es el caso para regular el ejercicio de los derechos fundamentales, y que los diversos numerales del articulo 19 se encargan de precisar. $Y$ a tal punto es exclusiva y excluyente esta atribución conferida al legislador que el mismo constituyente se ba encargado de modo explicito de prohibir que éste delegue en el Presidente de la República esa potestad legislativa en todo lo que se refiera a garantias constitucionales, esto es derechos fundamentales (art.61 inc. $2^{\circ}$ )."22

2 Soro Klass Fduardo, "La Lev y Reglamento: Sus Relaciones en el Derecho Chileno", en Revista lus Rrbblicum, $N^{\circ} 3,1999$, p. 34 . 
Por lo tanto, son igual de válidas las interpretaciones que realiza el Legislador y los Organismos de la Administración dotados de la facultad de interprear normas legales, con la salvedad establecida de manera expresa por el constituyente que sólo la ley regule, complemente, testrinja, imponga limitaciones u obligaciones a los derechos fundamentales, sin afectarlos en su esencia ni impedir su libre ejercicio. Sin embargo, no debemos olvidar que la ley tiene una jerarquia superior a las normas administrativas.

Sin perjuicio de lo anterior, es menester precisar que la interpretación que realiza el legislador sobre los preceptos legales goza de mayor generalidad y abstracción que la interpretación que les atañe a los Organismos de la Administración del Estado. En cuanto a la primera clase de interpretación, no se encuentra limitada en su extensión y alcance, esto es, el legislador puede interpretar la ley de un modo general y obligatorio en cualquier campo del ordenamiento jurídico, incluso más, puede interpretar la propia Carta Fundamental, con las limitaciones antes mencionadas, en especial los derechos fundamentales que emanan de la naturaleza humana.

Por otro lado, la interpretación que realizan los Organismos de la Adminiscración, no puede ser de carácter amplio o general para todo el ordenamiento jurídico, pues la interpretación administrativa se encuentra regulada o limitada por la competencia del Organismo Adminiscrativo titular de ella, esto es, el círculo de arribuciones que la Constitución o la ley fijan como propio del ejercicio de la autoridad para el conocimiento o resolución de determinados asuntos. Previo a la actuación, ha de haberle sido conferido el poder jurídico para actuar y si no lo posee su acto es nulo, por cuanto ha actuado sin competencia, sin atribución previa de dicho poder/potestad. ${ }^{33}$

A mayor abundarniento, la mayoría de los Organismos de la Administración del Estado que se encuentran investidos de facultades interpretativas se configuran juridicamente como instituciones autónomas, con personalidad juridica y de duración indefinida con competencia fiscalizadora o de control, "...como una actividad encaminada a determinar si un órgano uorganismo administrativo ha actuado como correspondia hacerlo segin los patrones objetivos que sirven de base al control, (.) ha de destacarse que el enfasis del legishador en la regulación de la función estatal de control no apunta precisamente en la actualidad hacia el control de la Administración del Estado, de suyo conocido, sino que se orienta más bien al que la Administración Pública realiza sobre la actividad privada,..." 2 .

Por lo tanto, la actividad interpretativa de los Organismos de la Administración del Estado se encuentra limitada de manera estricta e insostayable por la competencia propia de dichos organismos, porque recordemos que los Organos de la Administración actúan válidamente previa investidura regular de sus integrantes, dentro de su competencia y en la forma que prescriba la ley.

-3 Soto Kloss Eduardo, Derecho Administrativo, Bases Fundamentules. Principio de furidicidad. Ed Juridica, Santiago. 1996, T. II, p. 50.

24 Pantoja Bauza Rolando, La Organización Administrativa del Estudo. Ed. Jurídica, Santiago, 1998, p. 351-352. 
Empero no es menos cierto que dichos organismos pueden dictar normas de carácter general, pero supeditadas a la competencia atribuida por la Constitución o por la ley, así por ejemplo las superintendencias cuyo rol es tutelar las actividades económicas, es decir, "... que vele porque la actuación de los privados que comprometa el interés público se desarrolle dentro de ciertos parámetros previamente definidos, de modo que no incurran en abusos que perjudiquen gravemente a terceros o cometan infracciones al ordenamiento juridico." 25

Las actividades, transacciones y actuaciones que realizan los privados o mejor dicho los agentes del mercado, no pueden desarrollarse en absoluta libertad; el Estado se ha visto forzado a recurrir a la regulación de la actividad económica, esto es, a usar su poder para restringir las decisiones de los agentes económicos y de esta forma evitar los monopolios naturates por razones de previsión o seguridad social.

Si bien recordamos que la regulación económica que realicen los Organismos de la Administración del Estado sólo puede ser realizada por ley, no obstante, es una realidad evidente e indiscutible que el legislador fija las bases esenciales de cada área económica, dejando la especificación, interpretación y aplicación de dichas normas a la autoridad administrativa, por razones técnicas, generando un fenómeno de doble, triple o cuádruple regulación de una determinada materia.

1.1) Aplicación de la Ley de Procedimiento Administrativo a las Normas Interpretativas.

Como señalamos en su oportunidad, los Organos Administrativos con facultades de interpretación de la ley ejercen sus atribuciones a través de medios jurídicos propios, como son las circulares, las órdenes, instrucciones y los dictámenes.

En este punto es menester hacer una breve precisión, en primer lugar la mayoría de las leyes que otorgan potestades interpretativas a los organismos mencionados anteriormente, atañen al ámbiro interno del servicio. Así, las leyes hablan de órdenes, instrucciones y circular, todas normas que se relacionan con la potestad de mando y se vinculan con el principio de jerarquía que gobierna la Administración del Estado.

En este sentido, existe una relación de menor a mayor entre las normas, por ejempio, la circulares constituye una de las formas que reviste el ejercicio de la autoridad del poder de mando, es decir, la circular es el género y la instrucción u orden contenida en ella, la especie, esto es, por medio de una circular el Jefe de un Servicio determinado comunica a sus dependientes los criterios que deben seguir en determinadas materias, incluso en las interpretativas.

A mayor abundamiento, en cuanto al concepto y alcance de las circulares, la doctrina señala:

:5 Idem, p. 353 . 
"Las circulares o instrucciones de servicio, son prescripciones que los jefes de servicios dan a los funcionarios situados bajo su autoridad en lo concerniente a la interpretación y aplicación de las leyes y reglamentos. El alcance juridico de tales documentos es esencialmente diferente según que se les mire respecto de los funcionarios o respecto de los administrados, (...) respecto de los funcionarios, la circular tiene un carácter obligatorio, es decir, que ellos deben tener como exacta la interpretación de la ley que ha sido dada y que están obligados a conformarse a las directivas que en ellas están contenidas" 26

Sin embargo, respecto de terceros o particulares el efecto es diferente, teóricamente no es vinculante, aunque en la práctica es totalmente distinto, así la doctrina señala:

"Ante los administrados la circular no tiene ninguna fuerza obligatoria; ella es inoponible; en particular, la interpretación de la ley que ella hace no liga al administrado; sólo se impone a éste la ley en si y la interpretación que efectuan los tribunales, (...) en resumen La circular no aporta ningún elemento nuevo a la legalidad, sino una fuente de obligación jerárquica al interior de la administración. ${ }^{\text {"2. }}$

Ahora, anre la pregunta si la circular y las órdenes o instrucciones contendidas en ellas constituyen o no acto administrativo, siguiendo al autor citado precedentemente, podriamos decir que se trata de un acto administrativo, ya que emana directamente del poder de mando de los superiores jerárquicos. Sin embargo, con la entrada en vigencia de la Ley de Bases de los Procedimientos Administrativos, se dio un concepto amplio de lo que se debe entender por acto administrativo en el artículo $3^{\circ}$ : "Para los efecto de esta ley se entenderá por acto administrativo las decisiones formales que emitan los Organos de la Administración del Estado en las cuales se contienen declaraciones de voluntad, realizadas en el ejercicio de una potestad pública."

Y también constituyen acto administrativo los dictámenes o declaraciones de juicio, de constancia o de conocimiento que se realizan en el ejercicio de una competencia determinada; esta definición se debe complementar con el concepto de acro administrativo dado por el profesor Eduardo Soto Kloss, que lo concibe como: "Una ordenación racional unilateral emitida por un stijeto en ejercicio de función administrativa, que, destinada a satisfacer una necesidad pública concreta, produce efectos juridicos directos. ${ }^{28}$

Por lo tanto, si bien la definición de la ley es formal, sin contenido, el concepto dado por este autor nos permite decir que las instrucciones son actos administrativos, pues son decisiones formales, ya que nada menos que deciden sobre la forma como debe interpretarse una ley y que producen efectos jurídicos inmediatos en el funcionario público, pero a la vez consecuencias mediatas en el administrado, al cual se va a

¿ Caldera Delgado Hugo, Tratudo de Derecho Administrativo. Ed. Parlamento Ltda. Santiago, 2001, p. 358.

$\therefore$ Idem. p. 358 .

ss Soro Kluss Foduarda, "I a Noción de dete Administrativo en el Derecho Chileno, Lina Perspectiva Sustancial" en Ley $X^{\circ} 19.880$. Sobre Procedimientos Administracivos, Conferencias Santo lomás de dquino. Santiago, Noviembre de 2003 , p. 36 . 
aplicar la ley siguiendo el criterio sustentado en la circular, ya que de orra forma el funcionario público se va a ver sujeto a sanciones por el principio de jerarquía del servicio público.

Sin embargo, no se entiende cómo la Contraloría General de la República por medio del Dictamen $\mathrm{N}^{\circ} 39.353$ de septiembre de 2003, haya señalado que la atribución del Servicio de Impuestos Internos de interpretar administrativamente la ley, "no se enmarca en ninguno de los conceptos de acto administrativo que contiene el artículo $3^{\circ}$ de la Ley $N^{\circ} 19.880$, toda vez que se trata de una potestad normativa, reguladora, chyo ejercicio corresponde que sea ponderado exclusivamente por el servicio".

Siguiendo ese mismo criterio, arribaríamos a la conclusión de que rodos los Organismos de la Administración dotados de potestades interpretativas similares ponderan internamente sus actos, ya que éstos no se encuentran alcanzados por la Ley $\mathrm{N}^{\circ} 19.880$. En este sentido, dicho dictamen ha recibido duras críticas, al respecto:

"De esta manera cuando la ley del SII, asi como en otras instituciones regulatorias, se refiere a la palabra instrucción, incluyendo dentro de su contenido las facultades interpretativas y regulatorias, oponibles a los particulares, no corresponden a una orden de buen servicio, que si pueden considerarse excluidas de la loy $N^{\circ} 19.880$, pues estas facultades en verdad son actos administrativos de contenido normativo que deben estar expresamente sometidos a la precitada ley "29

En cuanto a los dictámenes no vamos a decir más, debido a que la ley de Procedimiento Administrativo expresamente los incluye dentro del concepto de acto administrativo.

Por to tanto, las circulares, instrucciones, órdenes y los dictámenes, que son las normas en las cuales por mandato legal se debe contener la interpretación administrativa se cncuentran cubiertas por la Ley de Procedimiento Administrativo $\mathrm{N}^{\circ} 19.880$, y por consiguiente por todas las garantías, principios y derechos que la mencionada norma establece, de los cuales sólo resaltamos algunos importantes, como el principio de contradictoriedad, de imparcialidad, de transparencia e impugnabilidad de los actos administrativos, entre otros.

Es útil también, mencionar los derechos de los administrados en el procedimiento administrativo, contenidos en el artículo 19 de la Ley $\mathrm{N}^{\circ} 19.880$, de los cuales rescatamos: el derecho a conocer en cualquier momento el estado de la tramitación del procedimiento; acceder a los documentos y actos; formular alegaciones; y cualquier otro que establezca la Constitución y las leyes, entre ellos todos los del Capítulo III de la Carta Fundamental, que sean aplicables.

29 Cordero Vega Luis, "Una Interpretación intolerable. Limirando la Ley de Procedimiento Adinitustracivo". Semana furidica, N ${ }^{\circ} 161$ (8-14 de diciembre de 2003), p. 2. 
Por último, otro tema importante que franquea la tey $N^{\circ} 19.880$, es el sistema de recursos administrativos, es decir, el recurso de reposición y jerárquico del artículo 59 , y el recurso extraordinario de revisión del artículo 60 de la ley. Todo lo anterior, teniendo presences los efectos suspensivos que plantea la sede administrativa frente a la judicial.

2.2) La Discrecionalidad Interpretativa y Su Control.

Como señalamos en el acápite anterior la labor que realiza el juez y la que realiza el funcionario público investido de potestades interpretativas es similar, pero no sinónima, debido a que el primero debe conocer, interpretar y juzgar materia relativas a un conflicto inter partes, sin efectos erga omnes. En cambio, el segundo debe interpretar un determinado precepto con mira a la satisfacción de una necesidad pública de carácter general, así lo reconoce la doctrina:

"Ciertamente la Administración en el ejercicio de la función de administración directa realiza una actividad muy semejante a la que llevan a cabo los tribunales: interpretar las normas y aplicatlas a un caso concreto, (..) una diferencia importante radica en la posición del sujeto que ejerce la uctividad. Mientras que los tribunales actúan desde una posición supra parte y de desinterés objetivo. La Administración actúa desde una posición de parte, pues lleva a cabo esa actividad de interpretación y aplicación de las normas con una finalidad de lograr la consecución de los intereses puiblicos especificos que le son propios de acuerdo con el Derecho." 30

Y es precisamente la finalidad del Estado y el comerido que debe cumplir la Administración lo que la convierte en el poder cuya función es satisfacer las necesidades, apreciar en concreto los hechos y aplicar el derecho para dar una solución a un problema. Es por ello y por la rapidez de los Organismos Administrarivos, que el ordenamiento jurídico los provee de la posibilidad de elección entre múltiples alternativas para dar solución a un problema concreto.

Si bien constitucionalmente rige el principio de juridicidad y sujeción estricta y directa por parte de todos los Organos del Estado a la Constitución, tanto en su ser como en su obrar, el fenómeno de la discrecionalidad se encuentra siempre presente en toda decisión que adopren tanto los Organismos de la Administración, como los jueces, ya que no existe una sola forma de satisfacer una necesidad.

La discrecionalidad se puede conceprualizar a grandes rasgos como la realización de elecciones entre diferentes alternarivas con la finalidad de ejercer una potestad conferida por el ordenamiento jurídico ${ }^{31}$. Y entre las caracterísscicas de la discrecionalidad podemos señalar las siguientes:

to Desdentado Daroca Fva, Ios Problemus del Control Judicial de La Discrecionulidad Técnica. Un estudio Critico de la Jurisprudencia. Ed. Civitas S.A Madrid, España, 1997, p. 25.

: En su sentido nacural y obvio, "Se dice de ta potestad gutwernativa en las funciones de su competencia que no escán regladas". www.rąe.s. LA 22.4 EDICION (2001). 
a) supone la adopción de decisiones dentro de un margen de libre apreciación dejado por el ordenamiento jurídico;

b) implica un acto de elección sobre la base de argumentos valorativos acerca de los cuales las personas razonables pueden diferir;

c) la elección se adopta siempre conforme a criterios valorativos extrajurídicos.

Sin perjuicio de lo anterior, la discrecionalidad siempre se trata o se estudia desde la faz de la decisión administrativa, esto es, se caracteriza por un funcionario público dotado de una competencia poco definida y potestades más o menos libres. Por lo tanto, el funcionario que toma una decisión dentro de las múltiples que el ordenamiento lo facultaba para adoptar, ejerce un comportamiento discrecional, esto es, "...un discemir, un distinguir, entre las múltiples circunstancias que rodean a un hecho-necesidad pública que satisfacer-y ello supone, exige y requiere un margen de apreciación sobre ellas a fin de decidir, (...) formarse un juicio definitivo sobre algo variado, algo que presenta variadas o multiples facetas..." 32

La discrecionalidad como decíamos se aborda jurídicamente como libre elección o margen de apreciación para tomar una decisión y no de otra forma. Al respecro la doctrina extranjera distingue entre dos tipos de discrecionalidad, una discrecionalidad en la interpretación y la otra discrecionalidad en la decisión o estratégica.

La primera clase de discrecionalidad no se encuentra tratada en nuestro medio ya que a la interpretación que realizan los Organismos de la Administración se la aborda como de segunda clase, lo cual es errado debido al sinnúmero de entes administrativos dotados de dichas facultades y no es desconocida la injerencia que tienen sus pronunciamientos en el mundo jurídico. La discrecionalidad interpretativa se presenca, "...cuando las disposiciones juridicas vienen expresadas con lenguaje indeterminado, (...) estaria propiciada por cómo dicen las cosas en la ley, (.-) la discrecionalidad interpretativa está representada formidablemente por los tan traidos conceptos indeterminados." 33

En cuanto a la forma de identificar la presencia de discrecionalidad administrativa interpretativa, el mismo autor nos da criterios que son perfectamente extrapolables a nuestro sistema normativo, entre ellos citamos los siguientes: "A saber, si en una disposición que confiere potestades discrecionales, los aspectos reglados (la existencia misma de la potestad, su extensión, la competencia para actuarla y el fin que necesariamente será puiblico), no aparecen consignados con suficiente precisión, eso abre un área para la discrecionalidad interpretativa." 34

22 Soto Kloss Eduardo, en el prólogo del libro de Pabło Alarcón Jaña, sobre Discrecionalidad Adminiscrariva, p. 7.

33 Igarrua Salaverría Juan, "Principio de Legalidad, Concepros Indeterminacless y Discrecionalidad Administrativa" en Revised Espanola de Derecho Administative. Civitas, $\mathrm{N}^{\circ} 92,1996, \mathrm{p} .541$.

:4 Idem, p. 542 . 
No profundizaremos en la discrecionalidad administrativa en la decisión, debido a que es un tema estudiado y cuyo controt por parte de los tribunales de justicia no está puesto en duda. Sin embargo, nos centraremos en la discrecionalidad interprerativa y trataremos de dar ciertas pautas que se deben tener presentes para su control.

La interpretación que realizan los Organismos de la Administración se plasma en actos adminiscrativos, que no son otra cosa que manifestaciones de la voluntad administrativa sobre una determinada materia. En esta parte no abordaremos a fondo el acto administrativo de interpretación, sólo nos abocaremos a analizar sus requisitos, entre ellos, en especial, la motivación.

Por medio de la interpretación administrariva se pueden producir un sinnúmero de situaciones que alteran la extensión de la potestad interprecariva, entre ellas cabe destacar las siguientes:

a) "A excusa de darle eficacia práctica a la norma y de explotar todas sus potencialidades, se excienden sus disposiciones hasta cubrir actuaciones administrativas que, en rigor, no encuentran respaldo expreso alguno en la ley;

b) No se reducen estos funcionarios a interpretar únicamente las especificas normas sectoriales afectas a su fiscalización, dentro de su respectiva competencia y especialidad técnica, sino que incursionan en la hermenéutica (por lo común extensiva) que aquellas otras disposiciones relativas al funcionamiento y atribuciones del mismo servicio, (...) no obstante que en sede administrativa la aclaración de estas últimas incumbe privativamente a la Contraloria General de la República;

c) En ausencia de puntos oscuros que aclarar, en verdad no se restringen en declarar el sentido de las leyes, sino que razonan con miras, o a alterar un estatuto jurídico anterior, (...) o a innovar en el ordenamiento vigente expresando su voluntad de mandar, prohibir o permitir." 35

El panorama es aun más desalentador si nos atenemos a algunos pronunciamientos de la jurisprudencia ejerciendo un control sobre la interpretación administrativa; en este sentido la Corte Suprema ha señalado: "De lo anteriormente dicho se deriva que la arbitrariedad y la ilegalidad consistirian en una equivocada interpretación de la ley.

Ahora bien, la interpretación que haga una autoridad al aplicar una ley no puede considerarse una arbitrariedad, a menos que contrarie abiertamente el tenor literal o implique un absurdo inaceptable a la razón... "(CS, 23 de junio de 1994. Rol № 23.217. Lexis Nexis $\mathrm{N}^{\circ} 12977$ ).

3 Arósica Maidonado ivàn, "Los Dictámenes y la lnterpretación de la Ley en Sede Administrativa" en Revistu de Actualidad furidica., No14, julio 2006, p. 153-154. 
Entonces, viene la pregunta: y qué sucede con las demás situaciones que no sean contrariar abiertamenre el texto legal o impliquen absurdo a la razón, que, como hemos visto, es materia de cada día.

Para responder a la pregunta anterior, es que planteamos que la solución está en concebir una noción de acto administrativo sustancial, como propone Eduardo Soto Kloss, esto es, "Una ordenación racional unilateral emitida por un sujeto en ejercicio de función administrativa, que, destinada a satisfacer una necesidad pública concreta, produce efectos juridicos directos." 36

Y dentro de este nuevo concepto de acto administrativo, debemos incluir algo que es fundamental en todo acto de interpretación, que es la fundamentación de la interpretación o que es lo mismo que decir, la necesaria motivación de los actos administrativos. Por lo tanto, es menester señalar que si bien hay discrecionalidad de la Administración al interprerar un determinado precepto, esto no puede ser una puerta abierta para que la Administración interprete la norma como se le plazca, y luego en virtud de dicho pronunciamiento condicione a sus organismos a actuar de una determinada manera y eventualmente aplique sanciones a los particulares.

Nosotros proponemos que el acto de interpretación se debe enmarcar dentro de un concepto sustancial de acto administrativo, como el anteriormente citado. Sin embargo, si realizamos una interpretación correcta del arriculo $3^{\circ}$ de la Ley $\mathrm{N}^{\circ} 19.880$, esto es, de la definición de acto administrativo, nos daremos cuenta que la ley se refiere a decisiones escritas y formales, en las cuales se contienen declaraciones de voluntad. En otras palabras, el acto de interpretación por ser un acto administrativo, o sea un acto de decisión por el cual la Administración manifiesta su voluntad, exige un ejercicio de la razón, una apreciación y una determinación, por lo tanto no puede ser infundada o carente de elementos de juicio, ya que de lo contrario no seria voluntad sino arbitrariedad.

Al interpretar, la Administración, deciamos, realiza una función cuasi judicial, no obstante al igual que los tribunales de justicia, los Organismos de la Administración deben sujetarse a ciertos cánones de interpretación generales para el ordenamiento juridico. Como señalábamos en la primera parte de este trabajo, las normas de interpretación que rigen la labor hermenéutica del juez deben aplicarse al derecho público, con las precisiones comentadas en esa ocasión, con mayor razón se deben aplicar al cometido hermenéutico que realizan los Organismos de la Administración, pues realizan una función similar; así por ejemplo, el funcionario público investido de potestades interpretativas debe conocer los hechos e interpretar la norma jurídica ocupando todos los elementos que franquean los arrículos 19 a 24 del Código Civil.

3) Soto Kloss Eduardo, "La .Voción de Acto Administrativo en el Derecho Chilento. Lina Perspecciva Sustancial" en Ley $\left.N^{\circ}\right] 9.880$, Sobre Procedinientos Adminisrativos. Conterencias Santo lomás de Aquino, Santiago. noviembre de 2003 , p. 36 . 
No sólo esos preceptos deben regir la tabor hermenéutica del administrador, sino que también los articulos 1560 a 1566 del mismo cuerpo normativo, especialmente lo relativo, por un lado, a que las cláusulas de los contratos se interpretan unas con otras para darte a cada una el sentido que mejor convenga al contrato en su totalidad; esto es perfectamente aplicable a la ley, es decir la ley debe interpretarse en su integridad tratando de darle sentido a cada una de sus piezas y por otro lado, lo relacionado con las cláusulas ambiguas que interprete la Administración deben aplicarse a favor de los administrados y no en su contra, por el principio pro administrado.

A estos criterios interpretativos se deben sumar los previstos en la Carta Fundamental, con especial ahínco en que la persona humana está por sobre el Estado siempre, incluso al interpretar administrativamente.

Para Soto Kloss que el acto se encuentre morivado quiere decir, un juicio o un dictamen de la razón, que está necesariamente provisto de fundamentación, normativa y fáctica, que obedece a una justificación, debidamente acreditada, en los hechos, "... racional no indica solamente conforme a la razón -y razón juridica, esto es la justificación en los hechos y en el Derecho, decisión debidamente motivada ofundamentada- sino también significa que la decisión contenida en el acto administrativo ha de ser proporcionada, (...) ello quiere decir que debe necesariamente existir una adecuación de medios a fin entre decisión/medio, y la satisfacción de la necesidad que la decisión pretende obtener/fin." 37

Los motivos son requisitos de la esencia del acto administrativo, pero generalmente se refiere a actos de decisión y no a actos de interpretación, lo cual es errado debido a que en el Estado de Derecho no se debe distinguir qué actos requieren motivación y cuáles no, por prohibirlo el principio de interdicción de la arbitrariedad y además porque no se sabría cómo piensa, sopesa y razona la Administración al interpretar.

Que la actividad administrativa sea discrecional, ello no quiere decir que sea arbitraria, esto es, carente de racionalidad, proporcionalidad y finalidad, en pocas palabras no ajustada a la razón. En este sentido debemos señalar que la interpretación administrariva al ser una labor de constante apreciación discrecional debe ser motivada y para ello proponemos que se le deben aplicar los mismos cricerios normativos que se utilizan para controlar la discrecionalidad de decisión, es decir la racionalidad, proporcionalidad y finalidad.

En este sentido, la interpretación debe ser racional, no puede conducir a absurdos, ya que toda interpretación que conduzca a soluciones irracionales debe ser desechada por el intérprete. $Y$ sobre el funcionario público que interpreta la norma jurídica sigue vigente todo el ordenamiento jurídico y por ello permanece sujeto a las normas interpretativas antes mencionadas.

3. Tderm, p. 38. 
A mayor abundamiento, "La Loy que ha otorgado a la Administración tal potestad de obrar no ha derogado para ella la totalidad del orden juridico, el cual, con su componente esencial de los principios generales, sigue vinculando a la Administración. No tiene sentido por ello pretender ampararse en una potestad discrecional para justificar una agresión administrativa al orden juridico... ${ }^{38}$

Otro límite a la interpretación es la proporcionalidad, esto es, la correcta adecuación de los medios a un fin, por lo tanto, la Administración, frente a una necesidad pública que satisfacer, debe adecuar los medios al fin que pretende cumplir. Ahora visto desde la perspectiva de la interpretación, ésta debe ser proporcional, es decir, la opción interpretativa que adopte el funcionario público debe guardar la debida armonia y correspondencia con la solución que se plantea, que no es otra cosa que una manifestación de la interpretación lógica que se debe hacer del ordenamiento jurídico.

En este sentido, la jurisprudencia ha confirmado lo anterior al señalar "Que en orden de los motivos, para que el acto objeto de control sea valido, debe existir una adecuada correlación entre la potestad ejerida y su fin especifico, la que se producirá solo en la medida que los presupuestos de hecho invocados concurran efectivamente y estén juridicamente bien calificados, cuestion que se resuelve en un juicio de valor relacionado con la proporcionalidad y razonabilidad de la sanción aplicada." (CS, 5 de julio de 2000. Microjuris, T. 97, N 2 , sentencias de derecho público).

Y por último, la finalidad, el objetivo, el para qué, es un límite a que debe ceñirse la interpretación administrativa ya que la ley que asigna potestades a la Administración establece un fin determinado que cumplir, como puede ser fiscalizar, controlar, etc., que en último caso no es otra cosa que servir a la persona humana.

Yotro límite, y casi siempre omitido, es la naturaleza de la cosas que condicionan toda actividad discrecional de la Administración, sea de decisión, sea de interprezación; así lo establece la doctrina más autorizada: "Toda potestad discrecional se apoya en una realidad de hecho que funciona como supuesto de becho de la norma de cuya aplicación se trata. Este hecho ha de ser una realidad como tal hecho, y ocurre que la realidad es siempre una: no puede ser y no ser al mismo tiempo o ser simultáneamente de una manera y de otra." is

La propuesta que hemos planteado es menester que los Organismos de la Administración la consideren, debido al enorme impacto que alcanza la fase interpretativa en el procedimienco administrativo, por lo que aplicar los controles propios de la decisión administrativa discrecional al acto de interpretación es un comienzo en la materia. A mayor abundamiento, ha sido la jurisprudencia la que ha impuesto límites a las facultades interprecativas de los Organismos de la Administración.

4 fdem, p. 31 . 
En este sentido, la Corte de Apelaciones de Santiago ha señalado que "Interpretar administrativamente en materia de su competencia, las leyes, reglamentos y demás normas que rigen a las personas o entidades fscalizadas, supone un mayor examen y cuidado, toda vez que la aludida interpretación debe entenderse restringida: por una parte, sólo a las materias de su competencia; y por la otra, con la limitación propia de la actividad jurisdiccional, particularmente, si la mencionada interpretación origina consecuencias patrimoniales cuyo conocimiento debe quedar fuera del ámbito natural y propio de un ente fuscalizador de naturaleza exclusivamente administrativa. "(CA. Stgo, 29 de octubre de 1997. Rol N ${ }^{\circ}$ 1158-97. Lexis Nexis No 20.526).

Por lo tanto, la interpretación administrativa debe ser estricta, restringida, no pudiendo jamás recurrir a la interpretación analógica, ni menos establecer sanciones o fjar o llevar a efecto medidas que limiten los derechos de las personas.

En cuanto, al control de la interpretación administrativa por parte de los tribunales, ello es una exigencia de un imperativo constitucional en un Estado de Derecho. Así, de conformidad con la Carta Fundamental, sólo a los Tribunales de Justicia les corresponde conocer, juzgar y ejecutar lo juzgado; en este sentido la Corte Suprema ha controlado la interpretación administrativa, señalando que dicha atribución no es un obstáculo al control judicial; "Que la interpretación administrativa efectuada por el Servicio de Impuestos Internos, en nada compromete la facultad saberana que tienen los Tribunales de Justicia para juzgar los casos sometidos a su conocimiento, pues corresponde a estos efectuar la interpretación legal que estime más adecuada segrin sus criterios y las normas de hermenéutica establecidas en el Código Civil." (CS, 3 de enero de 1979. Rol $\left.\mathrm{N}^{\circ} 13.426\right)^{\text {to }}$

Frente a la afirmación de que en nuestro ordenamiento jurídico no existen potestades discrecionales, sino que algunos elementos internos de la potestad que pueden ser discrecionales, podemos señalar que es correcta, tanto es asi que la doctrina más autorizada ha señalado:

"... La libertad de escoger tuna alternativa entre varias posibilidades igualmente justas no configura independencia, sino una actividad que se desarrolla dentro del marco del ordenamiento juridico (por ende limitado por los principios generales del derecho y las normas positivas que reglamentan los requisitos de los actos administrativos, entre los que corresponde ubicar el control sobre los supuestos de becho)." +1

Por último, para dar por cerrada esta parte de la investigación es menester señalar que la discrecionalidad tanto en la decisión, como en la interpretación, no puede no estar

"Wh En el mismo sentido, pero más recienre. puede versc otra sentencia que controla la interpretación de la Diteccion del Trabajo, por consricuirse en comisión especial, al interptetar instrumentos colectivos $\mathrm{c}$ individuales de rrabajo. CS, 29 de diciembre de 2004, Rol No 5704-2004. Lexis Nexis $N^{\circ} 31689$.

\1 Cassagne luan Carlos, "La Revisión de la Discrecionalidad Administrariva por el Poder fudicial": en Retrista Fipanola de Derecho fdeminissrativo. Civituss. ํo67, 1990, p. 54. 
sujeta a limitaciones, ya que el Estado de Derecho lo exige como un imperativo para de esta forma evitar perjuicios a la persona humana.

\section{Objeto de la Interpretación Administrativa}

En cuanto al objeto de la interpretación administrativa, en principio no debe diferir del objeto mismo de la interpretación que realizan los demás Órganos del Estado, esto es, legislativo y judicial, que no es otra cosa que aclarar y buscar el sentido y alcance de una norma jurídica determinada.

Ahora, en relación al para qué se inrerpreta la norma jurídica por los órganos antes mencionados, varía. Así, el legislador por mandato constitucional reiterado por la ley es el encargado de interprecar la ley de un modo generalmente obligatorio, para transmitir dicha interpretación auténtica al resto del ordenamiento jurídico. El juez, por otro lado, tiene como objetivo al interpretar, buscar la solución a un problema con auroridad de cosa juzgada.

En cambio, la Administración al interpretar puede tener un objeto distinro, el cual va a depender de la competencia especifica que le asigne a cada organismo la ley respectiva de creación. Si analizamos las normas jurídicas nos daremos cuenta que dichos entes tienen como función general servir de apoyo al gobierno en la regulación de la economía, decimos regulación aunque hacemos la advertencia de que la palabra está mal utilizada, porque quien regula las actividades económicas sólo puede ser el legislador por mandato del artículo19 No21 de la Carta Fundamental.

En esta labor de apoyo se puede enumerar una serie de organismos estatales, pero a nosotros nos inceresan los que cuentan con potestades inrerpretativas; en este sentido es úril traer a colación el DL N" 3.551 de 2 de enero 1981, el cual "Fija Normas sobre Remuneraciones y sobre Personal para el Sector Público" y establece una categoría general de instituciones fiscalizadoras, dentro de las cuales se comprenden, según el artículo $1^{\circ}$, la Contraloria General de la República, la Fiscalía Nacional Económica, el Servicio Nacional de Aduanas, la Dirección del Trabajo y la Superintendencia de Seguridad Social, e indirectamente, la Superintendecia de Bancos e Instituciones Financieras, el Servicio de Impuestos Internos y la Superintendencia de Valores y Seguros (Art. $1^{\circ}, 2^{\circ}$ y $19^{\circ}$ ).

Como bien señala Ferrada, el hecho que se engloben bajo la denominación, instituciones fiscalizadoras, a todos los organismos mencionados anteriormente, no quiere decir que se han definido criterios materiales de sistematización de la función regulatoria en su conjunto, sino que se aplica dicho concepto para determinar las remuneraciones que corresponden a los funcionarios de los entes fiscalizadores. ${ }^{2}$

12 Ferrada Börquez Juan Carlos, “Los Organos Reguladores de Accividades Fconúrnicas Relevances en Chile: Una Visión Panoramica”, en Revista Chilera de Derecho, Vol. 30 No2. 2003, p. 281. En tol mismo senrido Pantuja Rolando, La Organización Administrativa del Estado. Ed. Jurídica, Santiago, 1998, p. 351-360. 
Por lo tanto, podemos decir que la mayońa de los Organismos del Estado con porestades interpretativas, son a la vez Organismos Fiscalizadores, ya sea porque se encuentran regulados en el mencionado DL N³.551 de 1981, ya sea porque su propias leyes les encomiendan la función de fiscalizar, para lo cual los dotan de potestades normativas generales y específicas, además de ser ".... instituciones autónomas, especialmente en el plano funcional, (...) en el impedimento legal de que su decisiones sean revisadas por via jerárguica por otros órganos -ya que no bay superior jerárquico en la organización-, sin perjuicio de la operatividad de los mecanismos de tutela o supervigilancia indirecta que contempla el ordenamiento." ${ }^{43}$

Como podemos ver la competencia de los Organismos Administrativos con potestades interpretativas es la fiscalización de la actividad económica específica, para velar por el correcto desenvolvimiento de los agentes económicos en el mercado, y además por las razones explicadas con anteriotidad sobre lo técnico de ciertas áreas de la economía que exige la presencia de organismos que velen por los derechos de los usuarios.

Lo anterior ha sido teconocido por la docrrina nacional más reciente, en este sentido Luis Lizama, el cual sostiene que el objeto de la interpretación administrativa es "...me parece más pertinente entender que la interpretación administrativa es privativa de ciertos servicios publicos especialmente facultados por el sistema juridico para interpretar la ley, (.-) no se trata de cualquier servicio público sino de entidades fiscalizadoras cuya obligación es velar por la correcta aplicación de las leyes y cuya competencia interpretativa se les ha conferido para que en el ejercicio de sus facultades fiscalizadoras el personal de su dependencia aplique en forma coherente y uniforme la ley interpretada. (.) en otras palabras la ley faculta a estos órganos para interpretar la ley que les corresponde fscalizar, a fin de que el ejercicio de sus facultades inspectivas sea realizado satisfaciendo el derecho fundamental de igualdad ante la ley para sodos los sujetos fiscalizados. No es casualidad que la totalidad de los órganos públicos facultados para interpretar la ley tengan a la vez competencia para fiscalizar la aplicación de las normas que interpretan...

Por lo tanto, la labor de interpretación de los Organismos Administrativos debe estar encaminada a fiscalizar, esto es, criticar y traer a juicio las acciones u obras de alguien, en este caso de los agentes económicos que actúan en el radio de acción de dichos organismos. Por lo que, la interpretación que no esté encaminada a fiscalizar sino a objetivos distintos como: integrar la ley, imponer requisitos no previstos en la ley, interpretar contra texto expreso, etc., adolece de nulidad por exceso de poder, al extralimitarse de la comperencia que el ordenamiento juridico les ha previsto.

t3. ldem, p. 283.

* Lizama Poral Luis, La (Direcición del Trabajo: Lina Explicación de su facultad de Interpretar la Legislación Laboral Chilena. Tesis (Grado de Magister en Derecho), Lniversidad de Chile, Santiago, 1998, p. 14-i5. 
